\title{
Retraction
}

\section{Retracted: Combined Case of Blood-Injury-Injection Phobia and Social Phobia: Behavior Therapy Management and Effectiveness through Tilt Test}

\author{
Case Reports in Psychiatry \\ Received 4 August 2016; Accepted 4 August 2016 \\ Copyright (C) 2016 Case Reports in Psychiatry. This is an open access article distributed under the Creative Commons Attribution \\ License, which permits unrestricted use, distribution, and reproduction in any medium, provided the original work is properly \\ cited.
}

Case Reports in Psychiatry has retracted the article titled "Combined Case of Blood-Injury-Injection Phobia and Social Phobia: Behavior Therapy Management and Effectiveness through Tilt Test" [1]. The article was found to contain a substantial amount of material from published articles, some without citation, including the following:

Heimberg RG et al.: Psychometric properties of the Liebowitz Social Anxiety Scale. Psychological Medicine, 1999, 29, 199-212 (not cited);

Ayala ES, Meuret AE, Ritz T: Treatments for bloodinjury-injection phobia: a critical review of current evidence. J Psychiatr Res. 2009 Oct; 43(15):1235-42. doi: 10.1016/j.jpsychires.2009.04.008;

Lars-Göran Öst, Ulf Sterner: A specific behavioral method for treatment of blood phobia. Behaviour Research and Therapy Volume 25, Issue 1, 1987, Pages 25-29 doi: 10.1016/0005-7967(87)90111-2;

Lars-Göran Öst, Anita Jerremalm, Jan Johansson: Individual response patterns and the effects of different behavioral methods in the treatment of social phobia. Behaviour Research and Therapy. Volume 19, Issue 1, 1981, Pages 1-16 doi: 10.1016/0005-7967(81)90107-8;

Ryan C. Shorey and Gregory L. Stuart: Manualized Cognitive-Behavioral Treatment of Social Anxiety Disorder: A Case Study. Clin Case Stud. 2012 Feb 1; 11(1): 35-47. doi: $10.1177 / 1534650112438462$ (not cited).

\section{References}

[1] F. Ferenidou, T. Chalimourdas, V. Antonakis, N. Vaidakis, and G. Papadimitriou, "Combined case of blood-injury-injection phobia and social phobia: behavior therapy management and effectiveness through Tilt test," Case Reports in Psychiatry, vol. 2012, Article ID 368039, 7 pages, 2012. 